\title{
Vitamin C inhibits platelet expression of CD40 ligand
}

\author{
Pasquale Pignatelli ${ }^{\mathrm{a}}$, Valerio Sanguigni ${ }^{\mathrm{b}}$, Sciacca Giordano Paola ${ }^{\mathrm{a}}$, Emanuela Lo Coco $^{\mathrm{a}}$, \\ Luisa Lenti ${ }^{\mathrm{a}}$, Francesco Violi,* \\ ${ }^{\mathrm{a}}$ Department of Experimental Medicine and Pathology, University of Rome La Sapienza, Divisione IV Clinica Medica, Policlinico Umberto I, Viale del \\ Policlinico, 00185, Rome, Italy \\ ${ }^{\mathrm{b}}$ Department of Internal Medicine, University of Rome Tor Vergata, Rome, Italy
}

Received 13 September 2004; revised 16 February 2005; accepted 24 February 2005

Available online 23 March 2005

\begin{abstract}
Upon stimulation with agonists, platelets express CD40 ligand (CD40L), a transmembrane protein implicated in the initiation and progression of atherosclerotic disease. We have recently discovered that oxidative stress plays a major role in platelet CD40L expression. In this study, we sought to determine whether vitamin $\mathrm{C}$, a known antioxidant, is able to influence platelet CD40L expression. In vitro experiments were done by stimulating platelets with collagen in the presence or absence of vitamin $\mathrm{C}(50-100 \mu \mathrm{M})$ or vehicle as control. An in vivo study was done in 10 healthy subjects who were randomized to intravenous infusion of placebo or $1 \mathrm{~g}$ vitamin $\mathrm{C}$ for $45 \mathrm{~min}$ in a crossover design. At the end of infusion platelet $\mathrm{CD} 40 \mathrm{~L}$ and $\mathrm{O}_{2}$ - were measured. The in vitro study demonstrated that vitamin $\mathrm{C}$ dose dependently inhibited platelet CD40L expression without affecting agonist-induced platelet aggregation. In subjects treated with placebo no changes of platelet $\mathrm{CD} 40 \mathrm{~L}$ and $\mathrm{O}_{2}$ - were observed; conversely, vitamin $\mathrm{C}$ infusion caused a significant and parallel decrease of platelet $\mathrm{O}_{2-}$ $(-70 \%, P<0.001)$ and CD40L $(-68 \%, P<0.001)$. Platelet aggregation was not modified by either treatment. This study suggests that water-soluble antioxidants, which scavenge superoxide radicals, may reduce platelet CD40L expression.
\end{abstract}

(C) 2005 Elsevier Inc. All rights reserved.

Keywords: Vitamin C; Platelets; Free radicals/free-radical scavengers; Reactive oxygen species

\section{Introduction}

CD40 ligand (CD40L), a member of the tumor necrosis factor ligand family, is a transmembrane protein with proinflammatory and prothrombotic properties upon interaction with its receptor CD40 [1]. CD40L was primarily found on the immune system cells, and subsequently on macrophages, smooth muscle cells, endothelial cells, and platelets [1]. Upon agonist stimulation, platelets express CD40L that is then cleaved on the membrane surface and finally circulates in the soluble form [2]; it has been

Abbreviations: CD40L, CD40 ligand; sCD40L, soluble CD40L; PRP, platelet-rich plasma; FITC, fluorescein isothiocyanate; Mab, monoclonal antibodies; PBS, phosphate-buffered saline; BSA, bovine serum albumin; AU, arbitrary unit.

* Corresponding author. Fax: +3906 49970102.

E-mail address: Francesco.Violi@uniroma1.it (F. Violi). calculated that over $95 \%$ of circulating soluble CD40L (sCD40L) originates from platelets [2]. The mechanism accounting for CD40L expression by activated platelets is still unclear. Previous studies demonstrated that platelets produce reactive oxidant species, which in turn act as intracellular signaling molecules that amplify platelet response to agonists [3].

We have recently demonstrated that platelet production of $\mathrm{O}_{2}^{-}$is implicated in the expression of $\mathrm{CD} 40 \mathrm{~L}$, as platelet incubation with $\mathrm{SOD}$, which dismutases $\mathrm{O}_{2}^{-}$to $\mathrm{H}_{2} \mathrm{O}_{2}$, significantly decreased agonist-induced $\mathrm{CD} 40 \mathrm{~L}$ expression [4]. These findings were confirmed by an in vivo study performed in patients with a deficit of gp91phox, the central core of NADPH oxidase. These patients showed a CD40L down-regulation, suggesting that $\mathrm{O}_{2}^{-}$generated by NADPH oxidase activation elicits an up-regulation of CD40L [4].

These data induced us to seek whether natural antioxidants play a role in modulating platelet CD40L expression. 
We first performed an in vitro study to assess if vitamin $\mathrm{C}$, a water-soluble molecule that scavenges superoxide radicals [5], was able to influence platelet CD40L expression. For the first time, we herein report that vitamin $\mathrm{C}$ inhibits CD40L expression in vitro and in vivo.

\section{Methods}

\section{Platelet preparation and activation}

Blood samples were taken from healthy subjects who had fasted at least $12 \mathrm{~h}$ and were mixed with $0.13 \mathrm{M}$ Na citrate. Platelet-rich plasma (PRP) was prepared as previously described [3]. Unless otherwise reported PRP was stimulated at $37^{\circ} \mathrm{C}$ for $3 \mathrm{~min}$ with collagen $[4 \mu \mathrm{g} / \mathrm{ml}$ ) or thrombin $(0.1 \mathrm{U} / \mathrm{ml})$. Agonist-induced platelet aggregation (Born's method) was measured by light transmission (LT\%) difference between PRP and platelet-poor plasma.

\section{$\mathrm{O}_{2}^{-}$detection}

Superoxide anion $\left(\mathrm{O}_{2}^{-}\right)$production by PRP stimulated with agonists was measured by lucigenin $(5 \mu \mathrm{M})[3]$ and expressed as stimulation index (SI $=$ mean level of stimulated platelet luminescence/average level of luminescence in unstimulated platelets).

\section{CD40L and CD62P expression}

CD40L and CD62P expression on platelet membrane was analyzed using specific FITC-labeled monoclonal antibodies (Mab) as previously reported [4]. An irrelevant isotype-matched antibody (anti-IgG1) was used as a negative control.

Mab $(20 \mu \mathrm{l})$ was added to platelets $\left(200 \mu \mathrm{l}, 2 \times 10^{8} / \mathrm{ml}\right)$ previously fixed with $2 \%$ paraformaldehyde in phosphatebuffered saline (PBS) (0.1\% BSA) and incubated for $60 \mathrm{~min}$ at $4{ }^{\circ} \mathrm{C}$. The unbound $\mathrm{Mab}$ was removed by addition of $0.1 \%$ BSA phosphate-buffered saline and centrifugation at $500 \mathrm{~g}$ for 3 min (twice). Fluorescence intensity was analyzed on an Epics XL-MCL Cytometer (Coulter Electronics, FL) equipped with an argon laser at $488 \mathrm{~nm}$. For every histogram, 50,000 platelets were counted to evaluate the percentage of positive platelets. Antibody reactivity has been reported in an arbitrary unit (AU) obtained by multiplying the number of positive events obtained after platelet stimulation by the mean fluorescence observed when the specific Mab was used, and correcting against the values obtained in the unstimulated sample treated with the same antibody.

\section{Analysis of $s C D 40 L$}

After 10 min of PRP stimulation with agonists, the reaction was blocked by acidification of the medium with ACD (D-sodium hydrogen citrate, D-glucose, and citric acid), PRP was centrifuged (10 $\mathrm{min}$ at $360 \mathrm{~g}$ ), and the supernatant was stored at $-80^{\circ} \mathrm{C}$ until use. $\mathrm{sCD} 40 \mathrm{~L}$ was measured with a commercial immunoassay (Quantikine CD40 Ligand, R\&D Systems).

In vitro study

In the in vitro study, platelet suspension $\left(3 \times 10^{9} \mathrm{plt} / \mathrm{ml}\right)$ was treated with vitamin $\mathrm{C}$ (ascorbic acid, 25-100 $\mu \mathrm{M}$ ) or solvent as control $\left(30 \mathrm{~min}\right.$ at $\left.37^{\circ} \mathrm{C}\right)$ before activation for $\mathrm{O}_{2}^{-}$, CD40L, and sCD40L analysis (see Methods above).

In vivo study

We investigated whether a short-term administration of vitamin $\mathrm{C}$ could affect agonist-induced platelet CD40L and $\mathrm{O}_{2}^{-}$. To calculate the sample size of the study, we first measured agonist-induced platelet CD40L expression in 44 healthy subjects ( 24 males, 20 females; age, $32 \pm 4$ years); in this population, platelet CD40L expression was $32 \mathrm{AU} \pm$ 3.1. Assuming that vitamin $\mathrm{C}$ reduced platelet CD40L by $50 \%$, at least 9 patients for each group had to be evaluated $(\alpha=0.05,1-\beta=0.80)$. We planned a randomized, doubleblind, placebo-controlled crossover study in 10 healthy volunteers ( 5 females and 5 males; mean age, $30.5 \pm 1.0$ years, range 24-36 years) who provided their informed consent to participate in the study. All subjects were nonsmokers, had no risk factors for atherosclerosis, and had not taken any antiplatelet agents or antioxidant drugs in the previous month; a 10-day washout was scheduled between the two phases of the study. Collagen-induced platelet CD40L, sCD40L, $\mathrm{O}_{2}^{-}, \mathrm{CD} 62 \mathrm{P}$, and aggregation were determined at baseline and immediately after $45 \mathrm{~min}$ of intravenous infusion of vitamin $\mathrm{C}$ at $24 \mathrm{mg} / \mathrm{min}$ or placebo.

\section{Statistical analysis}

Unless otherwise reported data are expressed as means \pm SD. The comparison between variables in the in vitro study was analyzed by Student's $t$ test for unpaired data; the correlation study between CD40L expression and $\mathrm{O}_{2}^{-}$ formation was evaluated using the linear correlation analysis followed by ANOVA test.

\section{Results}

Compared to unstimulated platelets, agonists such as collagen and thrombin significantly increased platelet $\mathrm{O}_{2}^{-}$ formation and CD40L expression (Fig. 1); $\mathrm{O}_{2}^{-}$and $\mathrm{CD} 40 \mathrm{~L}$ were significantly correlated $(r=0.93, P=0.006)$ with collagen $(4 \mu \mathrm{g} / \mathrm{ml}, n=4)$ and $(r=0.85, P=0.005)$ with thrombin $(0.1 \mathrm{U} / \mathrm{ml}, n=4)$. A similar correlation was detected using several concentrations of collagen (1 to $8 \mu \mathrm{g} /$ $\mathrm{ml}$ ) or thrombin $(0.01$ to $1 \mathrm{U} / \mathrm{ml})$ (data not shown). Vitamin $\mathrm{C}$ dose dependently inhibited $\mathrm{O}_{2}^{-}$and CD40L (Figs. 1A-D). 


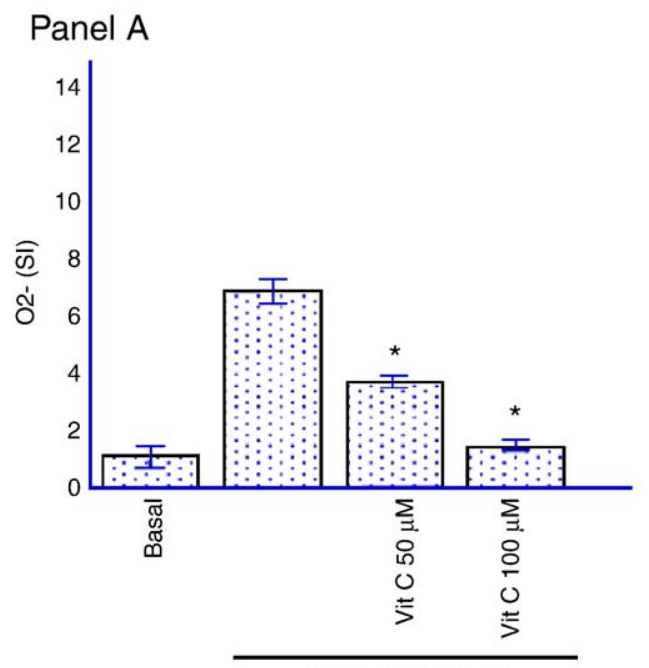

collagen $4 \mathrm{ug} / \mathrm{ml}$

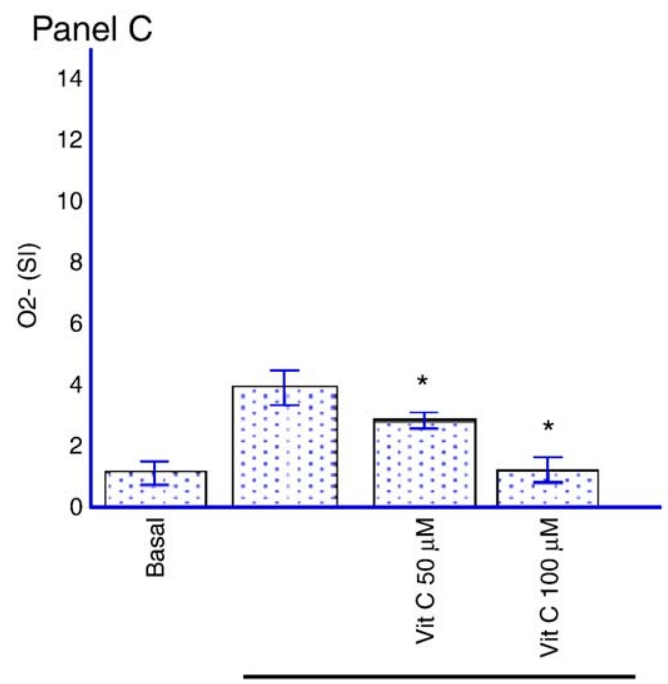

thrombin $0.1 \mathrm{U} / \mathrm{ml}$

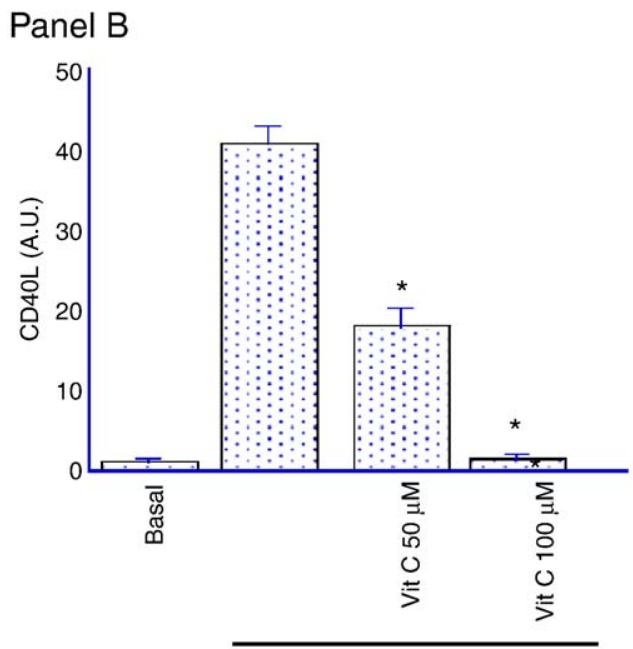

collagen $4 \mathrm{ug} / \mathrm{ml}$

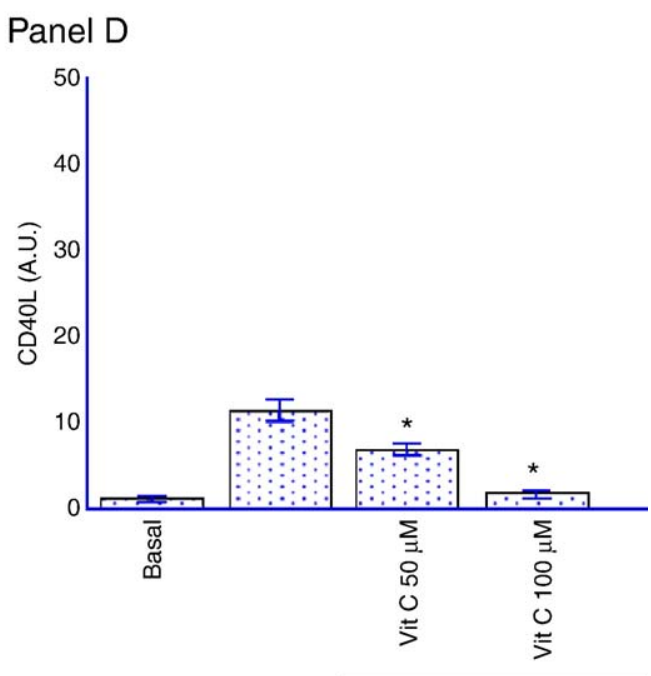

thrombin $0.1 \mathrm{U} / \mathrm{ml}$

Fig. 1. $\mathrm{O}_{2}^{-}$formation and CD40L expression in platelets treated with vitamin C. $\mathrm{O}_{2}^{-}$and $\mathrm{CD} 40 \mathrm{~L}$ formation in platelets incubated with and without vitamin $\mathrm{C}$ $\left(30 \mathrm{~min}\right.$ at $\left.37^{\circ} \mathrm{C}\right)$ and stimulated with collagen $(\mathrm{A}$ and $\mathrm{B})$ or thrombin $(\mathrm{C}$ and $\mathrm{D})$. Data $(n=5)$ are reported as means $\pm \mathrm{SD}$. The comparison between variables in the in vitro study was analyzed using the Student $t$ test for unpaired data $\left({ }^{*} P<0.01\right)$.

Platelet $\mathrm{O}_{2}^{-}$was inhibited by 50 and $93 \%$ with 50 and $100 \mu \mathrm{M}$ vitamin $\mathrm{C}$, respectively; platelet CD40L was inhibited by 52 and $96 \%$ with 50 and $100 \mu \mathrm{M}$ vitamin $\mathrm{C}$, respectively. Vitamin $\mathrm{C}$ also inhibited collagen-induced sCD40L formation in an dose-dependent fashion $(50 \mu \mathrm{M}=$ from $6.5+0.6$ to $3.18+0.02, P<0.001 ; 100 \mu \mathrm{M}=$ from $6.5+0.6$ to $0.45+0.01, P<0.001)$; conversely vitamin $\mathrm{C}$ did not affect either platelet aggregation or CD62P expression (data not shown). No change in $\mathrm{pH}$ value was observed in the platelet sample added with vitamin $\mathrm{C}$ (data not shown).

As phospholipase $\mathrm{A}_{2}$ (PLA2) and protein kinase $\mathrm{C}$ (PKC) have a role in enhancing $\mathrm{O}_{2}^{-}$production [3], we investigated the contribution of these enzymes in the production of $\mathrm{O}_{2}^{-}$elicited by agonist. Incubation of platelets with $\mathrm{RO} 318210\left(30 \mu \mathrm{M}, 37^{\circ} \mathrm{C} 30 \mathrm{~min}\right)$, an inhibitor of
PKC, or with AACOCF3 $\left(14 \mu \mathrm{M}, 37^{\circ} \mathrm{C} 30 \mathrm{~min}\right)$, an inhibitor of PLA2, resulted in $-23 \% P<0.05$ and $-93 \%$ $P<0.001$ platelet $\mathrm{O}_{2}^{-}$inhibition, respectively (Fig. 2).

At baseline subjects allocated to placebo or vitamin $\mathrm{C}$ had no significant difference in CD40L expression $(25.2+$ 6.0 vs $31.4+5.4$, respectively, $P>0.05)$ and $\mathrm{O}_{2}^{-}$production $(7.1+1$ vs $7.3+1$, respectively, $P>0.05)$.

In subjects receiving placebo, no changes in platelet CD40L $(25.2+6.0$ before and $25.6+6.0$ after $)$ and $\mathrm{O}_{2}^{-} \quad(7.1+$ 1 before and $7.4+3$ after) were observed (Fig. 2); conversely, subjects receiving vitamin $\mathrm{C}$ showed a reduction in platelet CD40L from $31.4 \pm 5.4$ to $8.9 \pm 3.8(-68 \%, P<0.001)$, and in $\mathrm{O}_{2}^{-}$from $7.2 \pm 1.11 .8 \pm 0.5(-70 \%, P<0.001)$ (Fig. 3). A parallel decrease in platelet $\mathrm{O}_{2}^{-}$and $\mathrm{CD} 40 \mathrm{~L}$ with a significant linear regression was observed $(r=0.86, P<0.001)$; similar findings were seen using thrombin as agonist (not shown). 


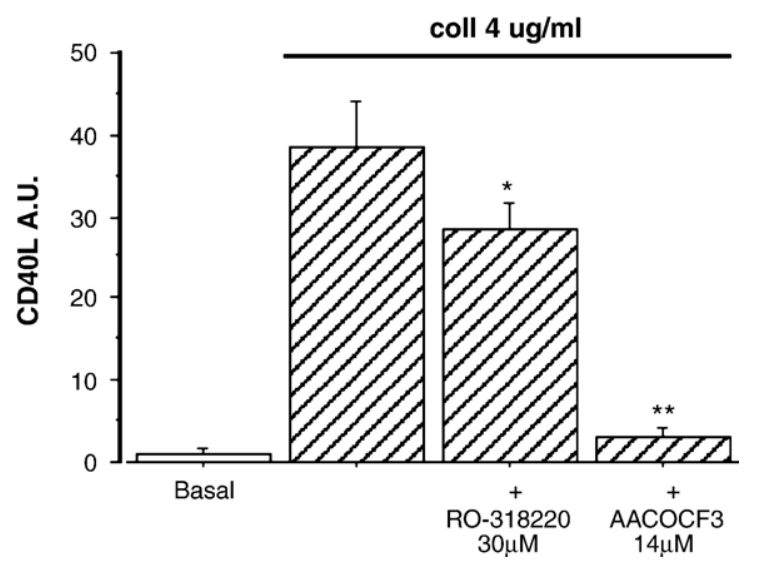

Fig. 2. Effect of PKC and PLA2 inhibitors on CD40L expression. CD40L expression in platelets stimulated with collagen and treated with or without PKC inhibitor RO-318220 or PLA 2 inhibitor AACOCF3. Data $(n=5)$ are reported as means $\pm \mathrm{SD} .\left({ }^{*} P<0.05 ;{ }^{* *} P<0.001\right)$.
sCD40L induced by platelet stimulation with collagen was unaffected in subjects given placebo (from $6.1 \pm 0.6$ to $5.7 \pm$ $0.7, P>0.05)$ while it was significantly inhibited in subjects given vitamin $\mathrm{C}$ (from $6.5 \pm 0.7$ to $2.2 \pm 0.5, P<0.001$ ). No changes in agonist-induced platelet aggregation or platelet CD62P expression were observed after either placebo (LT\% from $80+4$ to $79+6$ and CD62P from $8.9 \pm 1.3$ to $8.8 \pm 1.3$, $P>0.05$ ) or vitamin C infusion (LT\% from $82+3$ to $81+3$ and CD62P from $8.6 \pm 1.3$ to $8.3 \pm 1.2$ ).

\section{Discussion}

Several lines of evidence suggest that the CD40L/CD40 dyad is implicated in the pathogenesis of atherothrombosis. Thus, engagement of CD40L with its receptor CD40 induces several vascular responses that may potentially contribute to initiate and propagate the atherosclerotic lesion. In fact, CD40L enhances the expression of adhesive

Panel A
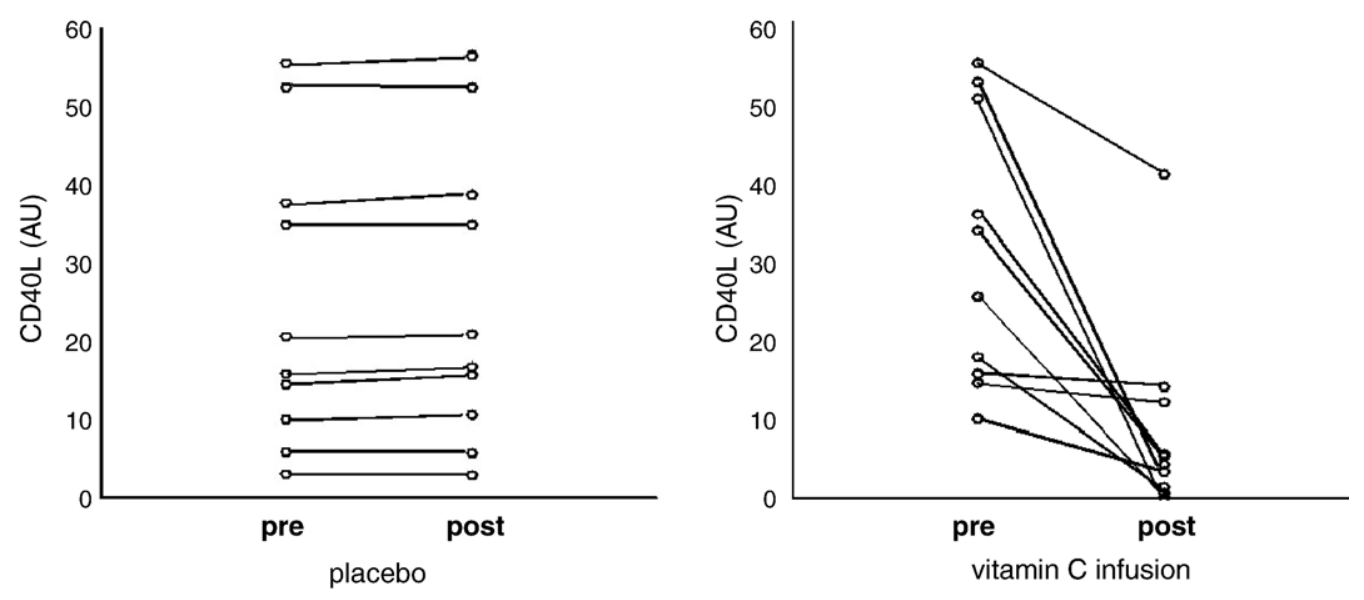

\section{Panel B}
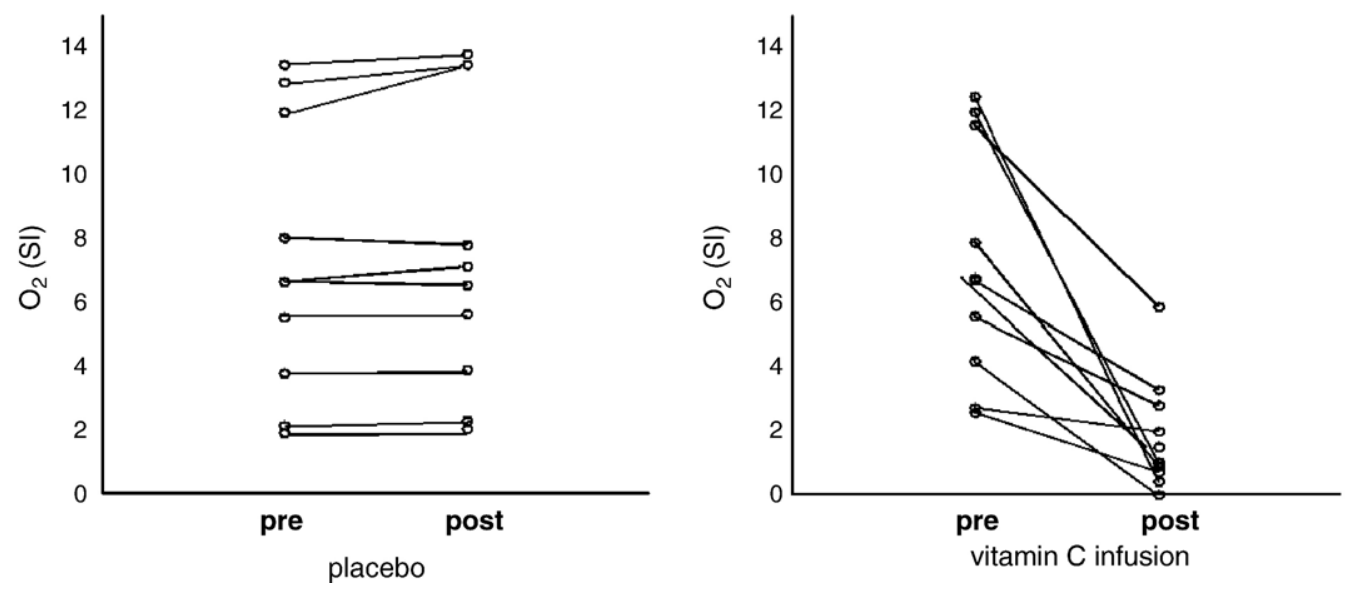

Fig. 3. Effect of placebo and vitamin $\mathrm{C}$ infusion on collagen-induced $\mathrm{O}_{2}^{-}$formation and $\mathrm{CD} 40 \mathrm{~L}$ expression in 10 healthy subjects. Collagen-induced $(4 \mu \mathrm{g} / \mathrm{ml})$ $\mathrm{CD} 40 \mathrm{~L}$ expression $(\mathrm{A})$ and $\mathrm{O}_{2}^{-}$formation (B) before (pre) and after (post) treatment with either vitamin $\mathrm{C}$ (right side) or placebo (left side). Data are expressed as means \pm SE. Student's $t$ test and linear regression analysis (ANOVA) were performed. Statistical significance was accepted at $P<0.05$. 
molecules, chemokines, metalloproteinases, and tissue factor [2]. An important support to the putative proatherosclerotic activity of CD40L was provided by an experimental study showing that antibodies against CD40L reduce the atherosclerotic lesion [6].

Observational, cross-sectional and prospective studies in humans suggested a role for $\mathrm{CD} 40 \mathrm{~L}$ in the pathogenesis of cardiovascular events that complicate the atherosclerotic disease. Thus, high levels of SCD40L have been described in patients at risk of cardiovascular events or in patients with acute coronary syndrome [1,8-10]; also, in patients with acute coronary syndrome, high levels of sCD40L were predictive of future cardiovascular events [10].

The mechanisms accounting for CD40L up-regulation are still unclear. Recent studies were focused on the possible role of oxidative stress in enhancing CD40L expression. Schonbeck and co-workers [7] demonstrated that incubation of human vascular endothelial cells and smooth muscle cells with oxidized LDL enhanced CD40 and $\mathrm{CD} 40 \mathrm{~L}$ expressions.

Another study conducted in patients with hereditary deficiency of gp91 phox, the central core of NADPH oxidase, reinforced the hypothesis that oxidative stress plays a role in CD40L expression [4]. These patients were characterized by an almost complete suppression of platelet $\mathrm{O}_{2}^{-}$production and by a significant reduction of platelet C40L expression compared to healthy subjects. Even if the exact mechanism through which oxidative stress enhances CD40L expression requires further investigation, these data suggested that antioxidants could be a useful tool to reduce it. To explore this hypothesis, we performed in vitro and in vivo studies to assess whether a natural antioxidant may influence platelet oxidative stress and CD40L. In vitro incubation of platelets with vitamin $\mathrm{C}$ inhibited CD40L expression in a dose-dependent manner. As vitamin $\mathrm{C}$ was able to inhibit platelet CD $40 \mathrm{~L}$ at concentrations that may be achieved in vivo following supplementation [11], we conducted an interventional study in healthy volunteers to evaluate whether this effect could be reproduced in vivo. This study demonstrated that the infusion of $1 \mathrm{~g}$ of vitamin $\mathrm{C}$ inhibited both platelet $\mathrm{O}_{2}^{-}$formation and $\mathrm{CD} 40 \mathrm{~L}$ expression, a phenomenon that was independent of agonist-induced platelet aggregation.

Together these data suggest that vitamin $\mathrm{C}$ inhibits the expression of platelet $\mathrm{CD} 40 \mathrm{~L}$ via reduction of platelet $\mathrm{O}_{2}^{-}$, the oxygen species that plays a crucial role in enhancing platelet CD40L [4] but does not provide definite data concerning the exact mechanism through which vitamin $\mathrm{C}$ exerts this antioxidant effect. Vitamin $\mathrm{C}$ could inhibit platelet production of $\mathrm{O}_{2}^{-}$and in turn $\mathrm{CD} 40 \mathrm{~L}$ through an enzymatic and/or a nonenzymatic mechanism. As vitamin $\mathrm{C}$ is able to scavenge superoxide radicals [5], inhibition of CD40L could depend on its capacity to quench $\mathrm{O}_{2}^{-}$as far as the enzymatic pathway is concerned. It seems unlikely, however, that vitamin $\mathrm{C}$ interferes with $\mathrm{PKC}$ as this enzyme seems to have a minor role in enhancing platelet
CD40L. Conversely, the rate of platelet CD40L inhibition by vitamin $\mathrm{C}$ is quite similar to that observed with the inhibitor of PLA2; this could suggest that vitamin C interferes with PLA2 activity but this hypothesis deserves further investigation.

In conclusion our data provide the first evidence that vitamin $\mathrm{C}$ inhibits platelet $\mathrm{CD} 40 \mathrm{~L}$ expression, probably by virtue of its antioxidant activity as suggested by a parallel decrease in platelet $\mathrm{O}_{2}^{-}$and $\mathrm{CD} 40 \mathrm{~L}$ following vitamin $\mathrm{C}$ infusion. While the mechanism eliciting platelet $\mathrm{O}_{2}^{-}$formation and $\mathrm{CD} 40 \mathrm{~L}$ expression deserves further investigation, these findings indicate that scavenging $\mathrm{O}_{2}^{-}$with vitamin $\mathrm{C}$ or other antioxidants having similar properties may represent a new therapeutic approach to reduce the proatherogenic properties of CD40L. We also suggest that platelet $\mathrm{CD} 40 \mathrm{~L}$ is a marker that may prove useful for monitoring the biological and clinical efficacy of antioxidants in the treatment of atherosclerotic disease.

\section{References}

[1] Schoenbeck, U.; Libby, P. The CD40/CD154 receptor/ligand dyad. Cell. Mol. Life Sci. 58:4-43; 2001.

[2] André, P.; Nannizzi-Alaimo, L.; Prasad, S. K.; Phillips, D. R. Plateletderived CD40L: the switch-hitting player of cardiovascular disease. Circulation 106:896-899; 2002.

[3] Pignatelli, P.; Lenti, L.; Sanguigni, V.; Frati, G.; Simeoni, I.; Gazzaniga, P. P.; Pulcinelli, F. M.; Violi, F. Carnitine inhibits arachidonic acid accumulation into platelet phospholipids. Effects on platelet function and oxidative stress. Am. J. Physiol. Heart Circ. Physiol. 284 (1):H41-H48; 2003.

[4] Pignatelli, P.; Sanguigni, V.; Lenti, L.; Ferro, D.; Finocchi, A.; Rossi, A.; Violi, F. gp91phox-dependent expression of platelet CD40 ligand. Circulation 110:1326-1329; 2004.

[5] Carr, A. C.; Zhu, B. Z.; Frei, B. Potential antiatherogenic mechanisms of ascorbate (vitamin C) and alpha-tocopherol (vitamin E). Circ. Res. 87:349-354; 2000.

[6] Mach, F.; Schonbeck, U.; Sukhova, G. K., et al. Reduction of atherosclerosis in mice by inhibition of CD40 signalling. Nature 394:200-203; 1998.

[7] Schonbeck, U.; Gerdes, N.; Varo, N.; Reynolds, R.S.; Horton, D.B.; Bavendiek, U.; Robbie, L.; Ganz, P.; Kinlay, S.; Libby, P. Oxidized low-density lipoprotein augments and 3-hydroxy-3-methylglutaryl coenzyme A reductase inhibitors limit CD40 and CD40L expression in human vascular cells. Circulation 106:2888-2893; 2002.

[8] Aukrust, P.; Muller, F.; Ueland, T.; Berget, T.; Aaser, E.; Brunsvig, A.; Solum, N. O.; Forfang, K.; Froland, S. S.; Gullestad, L. Enhanced levels of soluble and membrane-bound CD40 ligand in patients with unstable angina. Possible reflection of $\mathrm{T}$ lymphocyte and platelet involvement in the pathogenesis of acute coronary syndromes. Circulation 100:614-620; 1999.

[9] Varo, N.; de Lemos, J. A.; Libby, P.; Morrow, D. A.; Murphy, S. A.; Nuzzo, R.; Gibson, C. M.; Cannon, C. P.; Braunwald, E.; Schonbeck, U. Soluble CD40L: risk prediction after acute coronary syndromes. Circulation 108:1049-1052; 2003.

[10] Heeschen, C.; Dimmeler, S.; Hamm, C. W.; van den Brand, M. J.; Boersma, E.; Zeiher, A. M.; Simoons, M. L. CAPTURE Study Investigators. Soluble CD40 ligand in acute coronary syndromes. N. Engl. J. Med. 348:1163-1165; 2003.

[11] Weber, C.; Erl, W.; Weber, K.; Weber, P. C. Increased adhesiveness of isolated monocytes to endothelium is prevented by vitamin $\mathrm{C}$ intake in smokers. Circulation 93:1488-1492; 1996. 